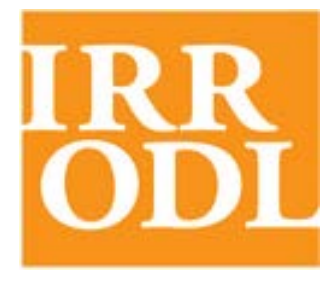

International

Review of

Research in Open

and Distance

Learning

Vol. 12.1

January -2011

\section{Prior Learning Assessment and Recognition: Emergence of a Canadian Community of Scholars}

\author{
Christine Wihak \\ Thompson Rivers University, Canada
}

\begin{abstract}
Prior learning assessment and recognition (PLAR) is the practice of reviewing, evaluating, and acknowledging the information, skills, and understanding that adult learners have gained through experiential or self-directed (informal) learning rather than through formal education (Thomas, 2000). As our current economy and workplaces experience rapid and continuing change, PLAR offers a vital contribution to supporting lifelong and life-wide learning (Evans, 2000). Beyond significant benefits to individual adult learners in terms of confidencebuilding and enhanced reflective capacity, PLAR's process translates personal and workplace learning into a portable format, a common coin suitable for public recognition in many different venues. PLAR has hence become an integral feature of lifelong learning policies around the globe and is closely linked with the implementation of national and transnational qualification frameworks (Morrissey et al., 2008).

PLAR scholars have a vital role in ensuring that policy and practice in this important field is informed by innovative research. This brief report describes a workshop on scholarly PLAR research, held in Ottawa, Canada on November 6 and 7, 2010 with funding from the Social Sciences and Humanities Research Council (SSHRC).
\end{abstract}

Keywords: Prior learning assessment and recognition; PLAR; research; lifelong learning; self-directed learning; experiential learning; national and transnational qualifications; Canada 


\section{Background}

In Canada, federal and provincial governments have recognized the importance of PLAR in a globalized knowledge economy (Morrissey et al., 2008). Policy makers appreciate its potential to contribute to economic and social development by re-skilling workers from dying industries, enhancing labour mobility, and integrating immigrant workers into the Canadian labour force. Both levels of government have sponsored demonstration projects on PLAR implementation in a range of industry sectors (e.g. nursing, tourism) and applied research projects on various aspects of PLAR. Recognizing potential benefits from PLAR for adult learners, provincial governments provide financial support for PLAR services for students in community colleges and in many provinces, in universities.

Given the high level of interest in PLAR amongst policy makers, a clear need exists for enabling and encouraging scholars to become critically engaged in this area. Two recent SSHRC awards, to Belisle and her colleagues (2008) and Conrad (2009), attest to the scholarly merit of PLAR research. Nevertheless, Canadian scholarly research on PLAR is scant. Van Kleef (personal communication) recently collected and analyzed Canadian PLAR research reports dating from 1995 to 2009. Although she identified over 80 qualitative and/or quantitative studies, only seven appeared in peer-reviewed journals (Austin, Galli, \& Diamantouros, 2003; Belanger \& Mount, 1998; Lordly, 2007; Peruniak \& Welch, 2000; Peruniak \& Welch, 2007; Van Kleef, 2006; Wihak, 2007) ${ }^{1}$. Eight of the 80 studies were masters or doctoral theses. These findings indicate that the large majority of PLAR research is taking place on the periphery of or completely outside of the scholarly community, without the benefit of the stimulation and critical review of the peer review process.

PLAR researchers recognize the importance of stimulating the growth of PLAR scholarship. One of the dilemmas facing PLAR researchers is that they represent many different disciplinary affiliations. Although adult education could be considered the discipline originally associated with PLAR (Thomas, 2000), researchers currently active in the field also come from other areas of education (higher education, vocational education, early childhood education), economics, management studies, medical disciplines (notably nursing), psychology, labour studies, and women's studies. PLAR scholars are thus challenged to keep abreast of advances in PLAR research that occur in so many different disciplines. This diversity also makes it difficult for PLAR scholars to convene in any regular way at discipline-focused scholarly events.

Recognizing the obstacles to cross-disciplinary scholarly discourse on PLAR, Thompson Rivers University has created the Prior Learning International Research Centre (PLIRC) (see http://www.tru.ca/distance/plirc.html). At PLIRC's inaugural meeting in July 2009, internationally known scholars presented papers on research activities in their geographic areas (Australia, Canada, EU, South Africa, UK, USA, and OECD member countries). Judy Harris, co-

\footnotetext{
${ }^{1}$ Because it was focused on Canadian research, Van Kleef's review did not include theoretical articles or review articles published in peer-reviewed journals (cf Conrad, 2008a, b) or international research coauthored by Canadian researchers (cf Andersson \& Guo, 2009).
} 
editor of the critically received book Retheorising the Recognition of Prior Learning (Andersson \& Harris, 2006), has edited the resultant collected papers with co-editors Dr. Mignonne Breier and Dr. Christine Wihak. Entitled Researching the Recognition of Prior Learning, the book will be published in 2011 by NIACE (National Institute for Adult Continuing Education). The papers provide a current international snapshot of PLAR research activities and findings. The endnote presents a synthesis of themes that emerged from the review of international research and suggests an international research agenda.

PLIRC provides updates on development in PLAR scholarship from around the world and hosts a members-only discussion forum. Special interest groups have begun to emerge within the PLIRC discussions (e.g., e-portfolio research).

\section{PLAR Research in Canada}

The fragmentation of the international PLAR field is mirrored in Canadian research. While a critical mass of PLAR scholars potentially exists, disciplinary differences impede the creation of an active community of scholarship. Not only do Canadian PLAR researchers lack the stimulation of an active community, the lack of community makes it challenging to find peer reviewers for grant applications and/or papers submitted to journals. Another serious issue is the difficulty of convening supervisory committees for graduate students, and this problem is becoming critical as PLAR scholars retire.

One venue where PLAR scholars do cross paths with some regularity is the Canadian Association of Prior Learning Assessment's (CAPLA) annual conference, although this is a practitioners' rather than a scholars' conference. That is, it is primarily an opportunity for public dissemination of policy developments and project findings, not an opportunity to engage in scholarly debate at a high level. Presentations at the CAPLA conference are not peer reviewed and hence have contributed little to the development of scholarly careers in Canada.

Because of the cross-disciplinary attraction of CAPLA and the opportunity to communicate research findings directly to practitioners, however, there is some advantage in maintaining a connection to the conference. Nevertheless, based on the understanding that PLAR scholars could benefit from a focused forum that could engage a community of scholars in the kind of discussion that would advance scholarly knowledge within the PLAR field, the research workshop "Prior Learning Assessment and Recognition: Emergence of a Canadian Community of Scholars” was held prior to the 2010 CAPLA conference. Intended to bring Canadian PLAR scholars together to build a PLAR research community and a Canadian PLAR research agenda, the workshop specified the following objectives:

- to map the territory of PLAR research currently being undertaken in Canada, including research by graduate students;

- to identify future directions for Canadian PLAR research and the contribution this research might make to the international research agenda developed by the PLIRC scholars; 
- to identify possible interprovincial and/or cross-disciplinary and/or international research projects that Canadian PLAR scholars could undertake.

A workshop format, rather than a conference, was chosen because given the current lack of an existing PLAR research community in Canada, a conference with this focus would be unlikely to attract significant numbers of scholars. Invited participants included Canadian scholars who had published on PLAR in the past five years, graduate students conducting research in this field, and two international PLAR scholars, Dr. Judy Harris from the UK and South Africa, and Dr. Nan Travers from the United States. The workshop format allowed the informal discussion and dialogue needed to develop a Canadian PLAR research agenda.

\section{Workshop Presentations ${ }^{2}$}

The workshop commenced with a keynote presentation from Dr. David Livingstone of the Ontario Institute for Studies in Education (OISE). His presentation offered information from a series of national surveys conducted from 1998 to 2010 on Work and Lifelong Learning. This data provided useful background on the Canadian public's interest in having their learning recognized through PLAR.

Ms. Joy Van Kleef, CEO of the Canadian Institute for Recognizing Learning and also a doctoral student, shared the results of her effort to identify and categorize Canadian English-language PLAR research. Dr. Rachel Belisle followed with a complementary presentation of Canadian Francophone research in the field, including her own. These two presentations gave grounds for cautious optimism that PLAR research is emerging as a distinctive field of study in Canada.

After these overview presentations, a number of scholars each shared his or her research. While several of the presenters shared a common background in adult education, their research interests with regard to PLAR were diverse. Dr. Angelina Wong presented on the relationship between research on service learning and PLAR in the university context. Dr. Shibao Guo framed his research on PLAR for immigrants in terms of recognitive justice. Dr. Dianne Conrad discussed the critical role of writing and language in the development of PLAR portfolios. Barbara Read shared the preliminary findings from her master's research on the role of informal and non-formal learning in higher education. Dr. Leah Moss reported on her doctoral work on PLAR in a military college setting.

Two presenters came from the health field. Elaine Santa Mina reported on work regarding development of an online instrument to use in determining degree equivalency of internationally educated nurses. Daphne Lordly provided a synthesis of several research studies she has conducted with regard to the use of PLAR in professional education for dietitians.

\footnotetext{
${ }^{2}$ Some of the attending scholars gave permission to have their presentations posted on the PLIRC website: http://www.tru.ca/distance/plirc.html.
} 
In the discussions that followed each presentation, various synergies among research interests emerged. For example, Guo's work with immigrants resonated with Santa Mina's work with internationally educated nurses. Belisle's work parallels Conrad's work in exploring the role of language in PLAR work. The two researchers from the health field realized they share common concerns and questions with regard to PLAR, even though they work in different health disciplines.

Harris' presentation of themes emerging from the upcoming PLIRC book on international PLAR research allowed the attending scholars to see how the state of PLAR research in Canada mirrors that of the international scene. This message was reinforced by Travers' presentation of PLAR research in the United States. In brief, to advance PLAR research in Canada and internationally, researchers in the field need to do the following:

1. consolidate the fragments in favour of cumulative research;

2. extend types of qualitative and quantitative research and the way we do mixedmethod research;

3. bring more and different theoretical lenses to PLAR research;

4. bring social science and economic research into dialogue;

5. strengthen links between policy (research) and scholarly research;

6. undertake more nuanced research - particular role-players, particular issues, bringing specialist and generalist research together;

7. train and mentor new researchers and form research partnerships (Harris, 2010).

Follow-up communication from workshop participants has indicated that the workshop succeeded in mapping the territory of Canadian scholarly research in PLAR, making the participants more aware of what research has been done or is in progress. Participants anticipate engaging in dialogue with each other individually about specific research interests and questions through membership in PLIRC. Several of the scholars have indicated a resolve to submit their work to peer-reviewed journals or books. Finally, the participants expressed an interest in congregating again in the future, possibly in conjunction with the Congress of the Social Sciences and Humanities, a major scholarly meeting held annually in Canada. A Canadian community of PLAR scholars has indeed begun to emerge. 


\section{References}

Andersson, P., \& Harris, J. (2006). Re-theorising the recognition of prior learning. Leicester, UK: National Institute of Adult Continuing Education.

Andersson, P., \& Guo, S. (2009). Governing through non/recognition: The missing ' $R$ ' in the PLAR for immigrant professionals in Canada and Sweden. International Journal of Lifelong Education, 28(3), 423-437.

Austin, Z., Galli, M., \& Diamantouros, A. (2003). Development of a prior learning assessment for pharmacists seeking licensure in Canada. Pharmacy Education, 3(2), 87-97.

Belanger, C. H., \& Mount, J. (1998). Prior learning assessment (PLA) in Canadian Universities. Canadian Journal of Higher Education, XXVIII(2/3), 99-120.

Belisle, R., et al. (2008). Espaces d'apprentissage d'adultes ayant obtenu une reconnaissance officielle d'acquis ou de compétences au secondaire. SSHRC grant.

Conrad, D. (2009). Relationship of knowledge building to the use of prior learning assessment within undergraduate degree programs: A comparative study. SSHRC grant.

Conrad, D. (2008a). Reflecting on strategies for a new learning culture: Can we do it? Journal of Distance Education, 22(3), 157-162.

Conrad, D. (2008b). Revisiting the recognition of prior learning: A reflective inquiry into RPL practice in Canada. Canadian Journal of University Continuing Education, 2(34), 89110 .

Evans, N. (2000). AP(E)L: Why? Where? How? Setting the international scene. In N. Evans (Ed.), Experiential learning around the world (pp. 15-29). London, England: Jessica Kingsley Publishers Ltd.

Harris, J. (2010, November 7). An international research agenda for PLAR. Presented at PLAR: Emergence of a Canadian Community of Scholars. Ottawa.

Lordly, D.J. (2003). Status of prior learning assessment in dietetic internship program. The Canadian Journal of Dietetic Practice and Research, 64, 207-212.

Morrissey, M., Myers, D., Bélanger, P., Robitaille, M., Davison, P., Van Kleef, J., \& Williams, R. (2008). Achieving our potential: An action plan for prior learning assessment and recognition (PLAR) in Canada. Ottawa: Canadian Council on Learning.

Peruniak, G., \& Powell, R. (2007). Back eddies of learning in the recognition of prior learning: 
A case study. Canadian Journal of University Continuing Education, 33(1), 83-106.

Peruniak, G., \& Welch, D. (2000). The twinning of potential: Toward an integration of prior learning assessment with career development. Canadian Journal of Counselling, 34, 232-245.

Thomas, A. (2000). Prior learning assessment: The quiet revolution. In A. Wilson \& E. Hayes (Eds.), Handbook of adult and continuing education (pp. 508-522). San Francisco: Jossey-Bass.

Van Kleef, J. (2007). Strengthening PLAR: Integrating theory and practice in postsecondary education. Canadian Journal of Applied Research in Learning, 1(2). British Columbia: Canadian Council on Learning. http://www.ccl-cca.ca/NR/rdonlyres/BEE4E097-4DF84960-8779-F4EA6D0CE52A/0/JARLArticle5sept07.pdf

Wihak, C. (2007). Prior learning assessment \& recognition in Canadian universities: View from the Web. Canadian Journal of Higher Education, 37, 95-112.

\section{Athabasca University $\mathbf{I}$}

